\title{
Change of government's subsidization policy improves smoking cessation services: a cross-sectional study from the perspectives of physicians
}

Tai-Yin Wu ${ }^{1,2+}$, Ling-Yu Hung ${ }^{3+}$, Wei-Chu Chie ${ }^{2}$, Tai-Yuan Chiu ${ }^{4^{*}}$ and Fei-Ran Guo ${ }^{4^{*}}$

\begin{abstract}
Background: The Taiwanese government increased financial subsidies for smoking cessation services in 2012. We aimed to evaluate the effects of this new policy on smoking cessation services from the physician's perspective.

Methods: This was a cross-sectional nationwide survey. Physicians who provided smoking cessation services for more than ten patient encounters in the preceding year of the new policy (February 2011 to March 2012) were recruited. The questionnaire was developed by two experts and was validated by a committee consisting of 11 delegates.

Results: We sent a total of 1,319 questionnaires. The response rate was $45.9 \%$. The majority of respondents were male $(88.4 \%)$, middle-aged (65.3\%), and worked as family physicians (56.1\%). Most physicians agreed that the new policy had increased the number of patients seeking smoking cessation, increased patients' willingness to adopt pharmacotherapy, helped physicians to prescribe medications, improved patients' adherence to medications, and improved quality of care. These changes were most prominent in medical centers. Changes in the practice of the 5As (ask, advise, assess, assist, arrange) were moderate. Among different medical settings, the most significant change was an increase in the expenditure on smoking cessation medications.
\end{abstract}

Conclusions: The new subsidization policy in Taiwan has improved smoking cessation services. Overall, physicians reported positive effects of the new policy. Further study is warranted to evaluate the long-term influence of the policy.

Keywords: Government's subsidization, Smoking cessation services, Cross-sectional study

\section{Background}

Tobacco use has reached epidemic levels around the world, resulting in a worldwide increase in tobaccorelated deaths and disabilities [1]. In 2012, smoking rates for men and women in Taiwan were 32.7 and $4.3 \%$, respectively [2]. Wen and colleagues report that smokingrelated diseases are responsible for a loss of 22 years' life expectancy in Taiwanese smokers [3].

There is strong evidence to support a need for tobacco control programs to decrease the health and economic burden of smoking [4]. An important strategy is to offer

\footnotetext{
* Correspondence: tychiu@ntuh.gov.tw; fjguo1@ntu.edu.tw

${ }^{\dagger}$ Equal contributors

${ }^{4}$ Department of Family Medicine, National Taiwan University Hospital \&

College of Medicine, Taipei, Taiwan

Full list of author information is available at the end of the article
}

help to quit tobacco use [5]. Article 14 of the World Health Organization Framework Convention on Tobacco Control (WHO FCTC) states that national policy or health insurance systems should make medications accessible and free, or at an affordable cost [6]. In the International Tobacco Control 4 Country Survey, under national financial policy (English Stop Smoking Services), U.K. smokers were more likely to achieve 28-day abstinence than those in Australia, Canada, and the United States [7].

The Taiwanese government has taken multiple approaches to reduce tobacco demand in different phases [8]. Since 2002, a tobacco health and welfare surcharge of NT\$5 (US\$0.14) per pack of cigarettes has been imposed [9], and subsidized tobacco cessation services that provide pharmacotherapy and brief counseling by physicians have been initiated [10]. Following the amendment 
of the Tobacco Hazards Prevention Act in 2009, smoking has been prohibited in virtually all indoor areas [11]. Over the years, the specialties providing smoking cessation services have evolved from family physicians and internists only to all medical specialties, including pediatrics, obstetrics, and psychiatry. Many Taiwanese physicians have been trained to help patients quit smoking, and smoking cessation has become a popular service [12]. The findings of the 2012 Adult Smoking Behavior Survey in Taiwan revealed that half of the responding smokers $(50.7 \%)$ had been urged by medical professionals to quit smoking [2]. The abstinence rates of the outpatients in one medical center were $99.7,49.2,37.7,30.2$, and $22.7 \%$, at $1,3,6,12$, and 36 months, respectively [9].

By 2012, smoking cessation services were available at 2,152 contracted medical institutions with a geographic coverage rate of $97 \%$ [2]. The physician fee was paid by the Health Promotion Administration (HPA) at a rate of NT\$250 (US\$8.33) per visit. Patients were responsible for a weekly out-of-pocket prescription co-payment of NT\$550 to NT\$1,250 (US\$18.33 to US\$21.67) [2]. However, this cost was still a potential hurdle for people on low incomes who intended to quit smoking.

To remove the economic barrier of smoking cessation service and lessen health inequality, the government started the Second-generation Cessation Payment Scheme (SCPS) in March 2012. The new policy is as follows: the patient's co-payment is $20 \%$ of the total medication cost and has an upper limit of NT\$200 (US\$6.67). The upper limit allows physicians to prescribe more expensive medications such as varenicline without being concerned about cost. Full subsidies are provided for smokers from low-income households. To encourage tracking of the smoking status of the patients, case management fees are also subsidized at NT\$100 (U\$3.33) per treatment course. Case managers have to call patients by telephone and report 7-day point prevalence rates at 3and 6-months. The new policy also includes some other changes. The maximum length of prescription is extended from 2 to 4 weeks, and cessation services are no longer restricted to outpatients but also serve inpatients and emergency room patients.

After SCPS, the number of smoking cessation patients increased by $41 \%$, from 83,724 during the year before its implementation to 117,989 during the year after implementation [13]. The 7-day point prevalence rate at 6 months increased from 22.8 to $28.0 \%$ [14]. However, we don't know the extent of these changes, such as the patient's willingness to adopt pharmacotherapy, patient's adherence to medication, and the quality of care. We also don't know the attitude of the physicians (positive or negative to the new policy), the barriers of implementation, and the change of the physicians' practice. In this study, we aimed to evaluate the impact of SCPS from the perspectives of physicians.

\section{Methods \\ Study design}

We conducted a cross-sectional nationwide questionnairebased survey.

\section{The participants}

We recruited 1,319 physicians who provided smoking cessation services for more than ten patient encounters in the preceding year of the new policy (February 2011 to March 2012). The physicians' roster was provided by the HPA, Ministry of Health and Welfare, Taiwan.

\section{The questionnaire}

The questionnaire was designed by two family physicians specializing in smoking cessation (FR Guo and LY Hung). An expert committee composed of 11 delegates from the Taiwan Association of Family Medicine, Taiwan Society of Internal Medicine, Taiwanese Society of Psychiatry, and HPA then collectively reviewed the questionnaire. A five-point Likert scale was used to encode the content validity of the questionnaire according to the importance and appropriateness of each item. The criterion of an average score of four or above was used to select the final items.

The questionnaire included five domains: patient changes, physicians' attitudes towards the new policy, barriers to implementation, changes in practicing the 5As (ask, advise, assess, assist, arrange), and institutional changes. Each domain was composed of five simple choice questions. Except for the domain of institutional changes, which were yes/no questions, the other four domains were five-point Likert scale choices. For these Likert-scaled questions, the choices were recorded as scores. A score of one meant strong disagreement while five meant strong agreement. The average score reflected the level of physicians' agreement with the statement. By combining the scores of the five questions in each domain, we obtained a summation index of each domain (including patient changes, physician attitudes, possible barriers, and practice of the 5As).

\section{The process of sending the questionnaires and collecting responses}

We mailed the questionnaires to each physician's practicing institution in July 2012. Physicians had to sign an informed consent before study participation. To improve the response rate, participants could respond in one of three ways: in a pre-paid return envelope, by facsimile, or by e-mail. We examined the questionnaires 2 weeks later and resent the same questionnaire in August to non-respondents. After collecting the last questionnaires on September 20, 2012, we started data analysis. Questionnaires without a physician's signature were excluded. A questionnaire was considered "valid" if it had less than 
three unanswered questions. A small gift of appreciation, a LED lamp, was sent to respondents who provided valid questionnaires.

\section{Statistical analysis}

Descriptive analysis was used for baseline characteristics and variables in the questionnaire. We examined the difference between respondents and non-respondents using a chi-square test. For multivariate analysis, we used baseline characteristics as independent variables and summation indexes as dependent variables. The correlations were examined by multiple regression models. To evaluate the institutional changes in different levels of medical settings, we further stratified our data according to settings, i.e., medical centers, regional hospitals, local hospitals, and primary care facilities. Chi-square tests were used to examine the differences. A p-value $<0.05$ for two-tailed tests was considered statistically significant. SPSS for Windows (IBM Company, New York, USA) was used for statistical analysis.

\section{Ethical approval}

This study was approved by the institutional review board (IRB) of Cardinal Tien Hospital, Taiwan. Only physicians who signed the informed consents were included in the analysis. Taiwan Association of Family Medicine is responsible for the certification of physicians and the researchers of this study have accessed the certification records. The researchers did not access patient records.

\section{Results}

We sent a total of 1,319 questionnaires. The response rate was $45.9 \%(n=605)$. The majority of the questionnaires were received by mail $(n=429,70.9 \%)$, followed by fax $(n=162,26.8 \%)$, and e-mail $(n=14,2.3 \%)$. Compared to non-respondents, respondents tended to be older, mostly family physicians, and mainly practicing in primary care settings (Table 1 ). The majority of respondents practiced in private institutions $(n=465,76.9 \%)$.

Table 2 presents the impact of the new subsidization policy to smoking cessation services. Most physicians agreed or strongly agreed that the new policy increased the number of patients engaging in smoking cessation treatment $(85.3 \%)$, and increased patients' willingness to adopt pharmacotherapy (55.0\%). For physicians' attitudes, more than $50 \%$ of respondents agreed or strongly agreed with all five items, including that the new policy was an improvement over the previous policy. The quality of care was also deemed to have improved. For possible barriers to the implementation of the new policy, the majority of physicians were neutral, and less than $50 \%$ agreed or strongly agreed with all five items. It was most difficult to track the abstinence rates of patients
Table 1 Baseline characteristics of the respondents and nonrespondents

\begin{tabular}{|c|c|c|c|c|c|}
\hline \multirow[t]{2}{*}{ Characteristics } & \multicolumn{2}{|c|}{$\begin{array}{l}\text { Respondents } \\
(n=605)\end{array}$} & \multicolumn{2}{|c|}{$\begin{array}{l}\text { Non-respondents } \\
(n=714)\end{array}$} & \multirow[t]{2}{*}{$p$} \\
\hline & $\mathrm{n}$ & (\%) & $\mathrm{n}$ & (\%) & \\
\hline \multicolumn{6}{|l|}{ Gender } \\
\hline Male & 535 & $(88.4)$ & 628 & $(88.0)$ & \multirow[t]{2}{*}{0.79} \\
\hline Female & 70 & (11.6) & 86 & $(12.0)$ & \\
\hline \multicolumn{6}{|l|}{ Age (years) } \\
\hline 39 and under & 103 & $(17.0)$ & 162 & $(22.7)$ & \multirow[t]{3}{*}{0.001} \\
\hline $40-59$ & 395 & $(65.3)$ & 470 & $(65.8)$ & \\
\hline 60 and over & 107 & $(17.7)$ & 82 & $(11.5)$ & \\
\hline \multicolumn{6}{|l|}{ Specialty } \\
\hline Family medicine & 339 & $(56.1)$ & 324 & $(47.7)$ & \multirow[t]{4}{*}{0.009} \\
\hline Internal medicine & 142 & (23.5) & 166 & $(24.4)$ & \\
\hline Psychiatry & 10 & $(1.7)$ & 17 & $(2.5)$ & \\
\hline Others & 114 & $(18.8)$ & 172 & $(25.3)$ & \\
\hline \multicolumn{6}{|l|}{ Practicing institution } \\
\hline Medical center & 25 & $(4.1)$ & 40 & (5.6) & \multirow[t]{4}{*}{$<0.001$} \\
\hline Regional hospital & 61 & $(10.1)$ & 190 & $(26.7)$ & \\
\hline Community hospital & 56 & (9.3) & 11 & $(1.5)$ & \\
\hline Primary care setting & 463 & $(76.5)$ & 471 & $(66.2)$ & \\
\hline \multicolumn{6}{|l|}{ Smoking status } \\
\hline Non-smoker & 531 & $(87.8)$ & - & - & \\
\hline Ex-smoker & 68 & $(11.2)$ & - & - & \\
\hline Current smoker & 6 & (1.0) & - & - & \\
\hline
\end{tabular}

(39.8\%) and least difficult to use the information system $(24.0 \%)$. Regarding the practice of the 5As, changes following the introduction of the new policy were moderate. The percentages of physicians who agreed or strongly agreed that the change in practice of the $5 \mathrm{As}$ was improved ranged from $44.2 \%$ (for arrange) to $48.7 \%$ (for assist), respectively.

We used multiple regression models to evaluate the correlation between baseline characteristics and four summation indexes (Table 3). Medical centers were the institution type most associated with patient changes, physician attitudes and practice of the 5As. Age and the specialty of family medicine were also associated with patient changes. The former had an inverse association while the latter had a positive association. No other variable of baseline characteristics was significantly associated with the summation indexes.

Table 4 presents institutional changes at different levels of medical setting. The most prominent change observed was an increase in expenditure on smoking cessation medications (52.9 \%). This change was consistent across different levels of settings. Only a few institutions reported an increase in smoking cessation personnel; 
Table $\mathbf{2}$ The impact of the new subsidization policy to smoking cessation services

\begin{tabular}{|c|c|c|c|c|c|c|}
\hline \multirow[t]{2}{*}{ Impact } & \multicolumn{2}{|c|}{$\begin{array}{l}\text { Strongly disagree \& } \\
\text { disagree }\end{array}$} & \multicolumn{2}{|c|}{ Neutral } & \multicolumn{2}{|c|}{$\begin{array}{l}\text { Agree \& strongly } \\
\text { agree }\end{array}$} \\
\hline & $\bar{n}$ & (\%) & $n$ & (\%) & $n$ & (\%) \\
\hline \multicolumn{7}{|l|}{ Patient changes } \\
\hline Increase in the number of smoking cessation patients & 58 & (9.6) & 31 & $(5.1)$ & 516 & (85.3) \\
\hline Increase in follow-up visits of smoking cessation patients & 206 & $(34.0)$ & 147 & (24.3) & 252 & $(41.6)$ \\
\hline Increase in patients' willingness to adopt pharmacotherapy for smoking cessation & 145 & $(24.0)$ & 127 & $(21.0)$ & 333 & (55.0) \\
\hline Increase in the number of smoking cessation patients referred by other patients & 173 & $(28.6)$ & 175 & $(28.9)$ & 256 & $(42.4)$ \\
\hline Increase in patients' abstinence rate & 129 & $(21.3)$ & 176 & $(29.1)$ & 299 & (49.6) \\
\hline \multicolumn{7}{|l|}{ Physician's attitudes towards the new policy } \\
\hline The new policy encourages more patients to quit smoking & 113 & $(18.7)$ & 130 & (21.5) & 362 & (59.8) \\
\hline The new policy helps me to prescribe smoking cessation medications & 71 & $(11.7)$ & 112 & (18.5) & 422 & $(69.8)$ \\
\hline The new policy improves patients' adherence to medications & 116 & $(19.2)$ & 173 & (28.6) & 315 & $(52.1)$ \\
\hline The new policy improves quality of care & 87 & $(14.4)$ & 176 & $(29.1)$ & 341 & (56.5) \\
\hline Overall, the new policy is an improvement over the previous policy & 87 & $(14.4)$ & 143 & (23.6) & 375 & (61.9) \\
\hline \multicolumn{7}{|l|}{ Possible barriers to the implementation of the new policy } \\
\hline Difficulties in providing services to inpatients and emergency room patients & 77 & $(12.7)$ & 304 & $(50.2)$ & 222 & $(36.8)$ \\
\hline Difficulties in tracking the abstinence rate of the patients & 161 & $(26.6)$ & 203 & (33.6) & 240 & (39.8) \\
\hline Difficulties in reimbursement and case report processes & 162 & $(26.8)$ & 270 & (44.6) & 172 & $(28.4)$ \\
\hline Difficulties in applying for case management fees & 138 & $(22.8)$ & 265 & (43.8) & 201 & $(33.2)$ \\
\hline Difficulties in using the information system & 182 & $(30.1)$ & 277 & (45.8) & 145 & (24.0) \\
\hline \multicolumn{7}{|l|}{ Changes in practicing $5 \mathrm{As}$ after the new policy } \\
\hline Increase in asking patients' tobacco use status & 85 & $(14.1)$ & 245 & $(40.5)$ & 274 & $(45.4)$ \\
\hline Increase in advising patients to quit smoking & 81 & $(13.4)$ & 230 & (38.0) & 293 & $(48.5)$ \\
\hline Increase in assessing patients' willingness to quit & 88 & $(14.5)$ & 225 & $(37.2)$ & 291 & $(48.2)$ \\
\hline Increase in assisting patients to quit smoking & 116 & $(19.2)$ & 194 & (32.1) & 294 & $(48.7)$ \\
\hline Increase in arranging follow-up visits & 97 & $(16.0)$ & 240 & $(39.7)$ & 267 & $(44.2)$ \\
\hline
\end{tabular}

however, medical centers had significantly greater increases in the numbers of physicians, case managers, and professional counselors providing smoking cessation services.

Comparing physicians' responses from different medical settings (data not shown), physicians at medical centers seemed to take a more positive attitude towards the new policy. However, they also encountered more difficulties in providing services to inpatients and emergency room patients.
For the reliability of the questionnaire, the Cronbach's Alpha of the domain of patient changes is 0.81 , physician's attitudes is 0.92 , barriers to implementation is 0.69 , and changes in practicing $5 \mathrm{As}$ is 0.88 , respectively.

\section{Discussion}

We observed that, in half a year, physicians reported that the new subsidization policy in Taiwan resulted in an increased number of patients, better prescription of medications, improved patient adherence, and improved quality

Table 3 Multiple regression models of summation indexes

\begin{tabular}{|c|c|c|c|c|c|c|c|c|}
\hline \multirow[t]{2}{*}{ Factor } & \multicolumn{2}{|c|}{ Patient changes } & \multicolumn{2}{|c|}{ Physician attitudes } & \multicolumn{2}{|c|}{ Possible barriers } & \multicolumn{2}{|c|}{ Practice ${ }^{a} 5 \mathrm{As}$} \\
\hline & $\bar{B}$ & $p$ & $\bar{B}$ & $p$ & $\bar{B}$ & $p$ & $\bar{B}$ & $p$ \\
\hline Physician's age & -0.03 & 0.045 & -0.02 & 0.25 & -0.01 & 0.89 & -0.01 & 0.55 \\
\hline Physician's gender: male & 0.05 & 0.93 & 0.16 & 0.77 & -0.23 & 0.55 & 0.88 & 0.06 \\
\hline Specialty: family medicine & 0.68 & 0.03 & 0.57 & 0.09 & 0.19 & 0.42 & 0.35 & 0.22 \\
\hline Institution: medical center & 2.94 & 0.001 & 3.36 & 0.001 & 1.13 & 0.06 & 2.34 & 0.001 \\
\hline Smoking status: non-smoker & 0.07 & 0.89 & 0.45 & 0.37 & -0.27 & 0.46 & 0.44 & 0.32 \\
\hline
\end{tabular}

${ }^{\mathrm{a}} 5 \mathrm{As}$ : ask, advice, assess, assist, arrange 
Table 4 The impact of new subsidization policy to institutional changes in different levels of medical settings

\begin{tabular}{|c|c|c|c|c|c|c|c|c|c|c|c|}
\hline \multirow[t]{2}{*}{ Impact } & \multicolumn{2}{|c|}{ Total $(n=605)$} & \multicolumn{2}{|c|}{$\begin{array}{l}\text { Primary care } \\
\text { settings }(n=463)\end{array}$} & \multicolumn{2}{|c|}{$\begin{array}{l}\text { Community } \\
\text { hospitals }(n=56)\end{array}$} & \multicolumn{2}{|c|}{$\begin{array}{l}\text { Regional } \\
\text { hospitals }(n=61)\end{array}$} & \multicolumn{2}{|c|}{$\begin{array}{l}\text { Medical } \\
\text { centers }(n=25)\end{array}$} & \multirow[t]{2}{*}{$p$} \\
\hline & $n$ & (\%) & $n$ & (\%) & $n$ & (\%) & $n$ & (\%) & $n$ & (\%) & \\
\hline Increase in smoking cessation clinics & 167 & $(27.6)$ & 125 & $(27.0)$ & 15 & (26.8) & 15 & $(24.6)$ & 12 & $(48.0)$ & 0.134 \\
\hline $\begin{array}{l}\text { Increase in physicians providing } \\
\text { smoking cessation services }\end{array}$ & 113 & $(18.7)$ & 66 & $(14.3)$ & 16 & $(28.6)$ & 14 & $(23.0)$ & 17 & $(68.0)$ & $<0.001$ \\
\hline $\begin{array}{l}\text { Increase in expense of smoking } \\
\text { cessation medications }\end{array}$ & 320 & $(52.9)$ & 249 & $(53.8)$ & 25 & (44.6) & 31 & $(50.8)$ & 15 & $(60.0)$ & 0.515 \\
\hline $\begin{array}{l}\text { Increase in case managers in charge } \\
\text { of the follow-up of patients }\end{array}$ & 97 & $(16.1)$ & 58 & $(12.6)$ & 14 & $(25.0)$ & 15 & $(24.6)$ & 10 & $(40.0)$ & $<0.001$ \\
\hline Increase in professional counselors & 76 & (12.6) & 42 & (9.1) & 10 & (17.9) & 13 & (21.3) & 11 & (44.0) & $<0.001$ \\
\hline
\end{tabular}

of care. These changes were in accordance with the reduced medication cost to the patients. The impact was more prominent in medical centers, and being a family physicians was also associated with overall ratings in patient changes.

There is substantial evidence for the efficacy of financial incentives for smoking cessation. In a Cochrane review, financial interventions had a favorable effect on abstinence at 6 months (Relative risk, RR: 2.45, $95 \%$ confidence interval, CI 1.17 to 5.12), the number of participants making an attempt to quit (RR: 1.11, $95 \% \mathrm{CI}$ 1.04 to 1.32 ) and the use of smoking cessation treatment (RR: 1.83, 95 \% CI 1.55 to 2.15) [15]. The incentive of reimbursement was the most significant factor affecting physicians' confidence and adherence to practice guidelines [12]. In Taiwan, the cost barrier was partially removed in 2002, when the Taiwanese government became the second in the world to reimburse smoking cessation, just behind England. In a cost-benefit analysis evaluating the Taiwanese smoking cessation services, the benefits far exceeded the costs after accounting for the different abstinence, relapse, and discount rates [16].

We proposed that if more than half (>50\%) of the responding physicians agreed or strongly agreed with a certain item, then such change was meaningful. It is worth noting that $52.9 \%$ of the physicians agreed that the expenditure on smoking cessation medications increased after the introduction of the new policy. Varenicline, a relatively new pharmacotherapy for smoking cessation [17], confers a higher abstinence rate of up to three years [18]. Varenicline is also more costly. Sueh et al. report that among U.S. Medicare beneficiaries, greater varenicline out-of-pocket expense is significantly associated with lower adherence and lower likelihood of receiving a refill (odds ratio, OR: $0.59,95 \% \mathrm{CI} 0.54$ to 0.66) [17]. Under the SCPS in Taiwan, physicians have more freedom to prescribe appropriate medication according to individual needs rather than being restricted by pharmaceutical prices. The prescription of varenicline increased dramatically after the introduction of SCPS. It is suggested that the increased abstinence rate may be associated with the increased use of varenicline [14]. In a way, the new policy has achieved its main goal: to remove the economic inequality.

The new policy has resulted in rises in the number of clinical visits and patients using smoking cessation services. More than four-fifths of physicians agreed or strongly agreed that the most striking change brought about by the new policy was an increase in patients. Case numbers increased by $41 \%$ after the implementation of the new policy [13].

Although the new policy has moderately changed the practice of the 5As, physicians in medical centers took a more positive attitude towards the new policy. This is probably because medical centers are more apt to allocate human resources to smoking cessation services, including physicians, case managers, and professional counselors. Medical centers also experienced greater changes with respect to the domains of patient changes, physicians' attitudes and practice of the 5As. The medical centers in Taiwan are different from those in the western countries. A medical center not only provides intensive care, cancer treatment and specialty consultations, it also provides large volume of outpatient services. A patient may walk in a medical center without referral. Therefore, the medical centers in Taiwan may provide more accessibility to smoking cessation services as compared to those in many western countries.

The majority of the physicians were neutral about possible barriers to the new policy, probably because the smoking cessation service has been in operation since 2002. Physicians are already familiar with the computerized information system and have little difficulties in using it. Physicians in hospitals experience more difficulties in providing services to inpatients and emergency room patients. Though the new policy extends services to these two patient groups, there are greater barriers of implementation.

We recruited physicians who might have higher levels of performance and self-efficacy in assisting patients to quit smoking. Physicians with better confidence might be more compliant with practice guidelines [19]. Just like 
previous surveys, family physicians were more likely to respond than internists [12], probably due to more training in counseling skills [20]. Family physicians also experienced more favorable patient changes. Younger physicians who have undergone newer training programs might be more familiar with the issue of smoking cessation. Ulbricht $S$ et al. reported younger general practitioners provided more smoking cessation counseling [21]. In our study, younger physicians reported more patient changes compared to their older peers.

This study has certain strengths. We obtained a nationwide representative list of physicians providing smoking cessation services. Our study might more accurately reflect the true picture of daily practice in different medical settings than previous studies. To increase response rate, we allowed for different ways of responding. It is well recognized that Taiwanese physicians are reluctant to answer questionnaires [12]. Compared to similar surveys targeting physicians providing smoking cessation services, which had a $38 \%$ response rate in 2007 or $6.7 \%$ in 2011 (unpublished data), this study had the highest response rate $(45.9 \%)$ among the studies carried out by the Taiwan Association of Family Medicine. We evaluated service changes as well as changes at different institutional levels. As far as we know, this is the first study to compare smoking cessation attributes across different medical settings.

Certain limitations existed, such as the presence of selection bias. Our participants might be more in favor of the new policy compared to non-respondents. There were differences in baseline characteristics between respondents and non-respondents, and the study's conclusions might not be generalizable to the whole population. We were not able to achieve long-term follow up, particularly with respect to the decline in smoking rates. We enrolled only physicians providing smoking cessation services, who tend to be more supportive of policies that favor such practices. The attitude of physicians not enrolled in smoking cessation services remains unknown. The Chinese culture makes people tend to choose the "right" answer rather than the objective truth, therefore, we might have overestimated the positive effects of the new policy.

Future studies may include physicians who are less engaged in smoking cessation services, but play important roles in tobacco control, such as pulmonologists and cardiologists. Future studies may also focus on costbenefit analysis, or the influence of more expensive treatments such as varenicline and combination nicotine replacement therapy. Since this study was carried out shortly after the implementation of the new policy, it is not known whether the attitudes of physicians would change over time. Potential changes in physician attitudes could be examined in future longitudinal studies.

\section{Conclusions}

We observed that the Second-generation Cessation Payment Scheme in Taiwan improved smoking cessation services. Overall, physicians agreed that the effects of the new policy were positive. The enactment of the new reimbursement policy seems to have attained its goal of promoting smoking cessation in the short term. Subsequent follow up is mandatory to evaluate the long-term effects.

\section{Availability of data and materials}

The dataset supporting the conclusions of this article is available in the Open Science Framework repository at https://osf.io/dkvtw/.

\section{Abbreviations \\ 5As: ask, advise, assess, assist, arrange; Cl: confidence interval; HPA: Health Promotion Administration; NT\$: new Taiwan dollar; OR: odds ratio; RR: relative risk; SCPS: second-generation cessation payment scheme; WHO FCTC: World Health Organization Framework Convention on Tobacco Control.}

Competing interests

The authors declare that they have no competing interests.

\section{Authors' contributions}

TY Wu drafted the manuscript. FR Guo and LY Hung conceived the study, contributed in the study design and acquisition, analysis and interpretation of the data. TY Chiu and WC Chie revised the manuscript critically for important intellectual content. All authors read and approved the final manuscript.

\section{Acknowledgements}

The authors thank Yu-Wen Peng and Mei-Ru Chen, the research assistants of the Taiwan Association of Family Medicine. The authors also thank the expert committee of the Taiwan Association of Family Medicine, Taiwan Society of Internal Medicine, and the Taiwanese Society of Psychiatry. This study is based on the data from the training program of smoking cessation, provided by the HPA, Ministry of Health and Welfare, Taiwan. The descriptions or conclusions herein do not represent the viewpoint of the Administration.

\section{Funding}

This study was supported by a grant from the Health Promotion Administration (CCY-101004) and the Health and Welfare Surcharge of Tobacco Products, Ministry of Health and Welfare, Taiwan.

\section{Author details}

${ }^{1}$ Department of Preventive Medicine, Renai Branch, Taipei City Hospital, Taipei, Taiwan. ${ }^{2}$ Institute of Epidemiology and Preventive Medicine, College of Public Health, National Taiwan University, Taipei, Taiwan. ${ }^{3}$ Department of Family Medicine, Yonghe Cardinal Tien Hospital, New Taipei City, Taiwan. ${ }^{4}$ Department of Family Medicine, National Taiwan University Hospital \& College of Medicine, Taipei, Taiwan.

Received: 12 November 2015 Accepted: 29 April 2016

Published online: 17 May 2016

References

1. Li IC, Lee SY, Chen CY, Jeng YQ, Chen YC. Facilitators and barriers to effective smoking cessation: counselling services for inpatients from nurse-counsellors' perspectives-a qualitative study. Int J Environ Res Public Health. 2014;11(5):4782-98.

2. Health Promotion Administration, Ministry of Health and Welfare, Taiwan. Taiwan Tobacco Control Annual Report. 2013. http://tobacco.hpa.gov.tw. Accessed 24 Oct, 2015

3. Wen CP, Tsai SP, Chen CJ, Cheng TY. The mortality risks of smokers in Taiwan: Part I: cause-specific mortality. Prev Med. 2004;39(3):528-35. 
4. Fosson GH, McCallum DM, Beeson DH. The health and economic consequences of cigarette smoking in Alabama, 2009-2010. Public Health Rep. 2014;129(6):486-90.

5. World Health Organization. WHO Report on the Global Tobacco Epidemic 2008. http://apps.who.int/iris/bitstream/10665/43818/1/9789241596282_eng. pdf. Accessed 24 Oct 2015

6. World Health Organization. WHO Framework Convetion on Tobacco Control. 2003. http://apps.who.int/iris/bitstream/10665/42811/1/9241591013. pdf. Accessed 24 Oct 2015.

7. Gibson JE, Murray RL, Borland R, Cummings KM, Fong GT, Hammond D, et al. The impact of the United Kingdom's national smoking cessation strategy on quit attempts and use of cessation services: findings from the International Tobacco Control Four Country Survey. Nicotine Tob Res. 2010;12(Suppl):S64-71.

8. Cox B, Vangronsveld J, Nawrot TS. Impact of stepwise introduction of smoke-free legislation on population rates of acute myocardial infarction deaths in Flanders, Belgium. Heart. 2014;100(18):1430-5.

9. Hsueh KC, Chen CY, Yang YH, Huang CL. Smoking cessation program in outpatient clinics of Family Medicine Department in Taiwan: a longitudinal evaluation. Eval Health Prof. 2010;33(1):12-25.

10. Chang FC, Hu TW, Lo SY, YU PT, Chao KY, Hsiao ML. Quit smoking advice from health professionals in Taiwan: the role of funding policy and smoker socioeconomic status. Tob Control. 2010;19(1):44-9.

11. Wu TY, Chie WC, Lai MS, Chen CC, Kuo KL, Majeed A. Knowledge of the new Tobacco Hazards Prevention Act is associated with smokers' behavior of seeking help in smoking cessation in Taiwan. Asia Pac J Public Health. 2015;27(2):NP212-22.

12. Guo FR, Hung LY, Chang CJ, Leung KK, Chen CY. The evaluation of a Taiwanese training program in smoking cessation and the trainees' adherence to a practice guideline. BMC Public Health. 2010;10:77.

13. Health Promotion Administration, Ministry of Health and Welfare, Taiwan. The new case number of smoking cessation since Sep. 2002 to May 2015. http://ttc.hpa.gov.tw/quit/SysE/E0301M01.asp. Accessed 24 Oct 2015

14. Lai CK. Financing policy, service distribution and abstinent outcomes of Taiwan Cessation Treatment Services in primary care. https://www.ntuh.gov.tw/en/FM Pages/CK-Lai-2015-WONCA-AP-Conference.aspx. Accessed 25 Oct 2015.

15. Reda AA, Kotz D, Evers SM, van Schayck CP. Healthcare financing systems for increasing the use of tobacco dependence treatment. Cochrane Database Syst Rev. 2012;6:CD004305.

16. Chen PC, Lee YC, Tsai ST, Lai CK. A cost-benefit analysis of the outpatient smoking cessation services in Taiwan from a societal viewpoint. Nicotine Tob Res. 2012;14(5):522-30.

17. Suehs BT, Davis C, Galaznik A, Joshi AV, Zou KH, Patel NC. Association of out-of-pocket pharmacy costs with adherence to varenicline. J Manag Care Spec Pharm. 2014;20(6):592-600.

18. Hsueh KC, Hsueh SC, Chou MY, Pan LF, Tu MS, McEwen A, et al. Varenicline versus transdermal nicotine patch: a 3-year follow-up in a smoking cessation clinic in Taiwan. Psychopharmacology. 2014:231(14):2819-23.

19. Schnoll RA, Rukstalis M, Wileyto EP, Shields AE. Smoking cessation treatment by primary care physicians. An update and call for training. Am J Pre Med. 2006;31:233-9.

20. Block DE, Hutton KH, Johnson KM. Differences in tobacco assessment and intervention practices: a regional snapshot. Prev Med. 2000;30:282-7.

21. Ulbricht S, Meyer C, Schumann A, Rumpf HJ, Hapke U, John U. Provision of smoking cessation counseling by general practitioners assisted by training and screening procedure. Patient Educ Couns. 2006;63:232-8.

\section{Submit your next manuscript to BioMed Central and we will help you at every step:}

- We accept pre-submission inquiries

- Our selector tool helps you to find the most relevant journal

- We provide round the clock customer support

- Convenient online submission

- Thorough peer review

- Inclusion in PubMed and all major indexing services

- Maximum visibility for your research

Submit your manuscript at www.biomedcentral.com/submit
Biomed Central 